\title{
Nutrir la identidad: la herencia china en la costa de Chiapas, México
}

\author{
Miguel Lisbona
}

\author{
Centro Peninsular en Humanidades y en Ciencias Sociales (Mérida, Yucatán), UNAM \\ mlisbonag@hotmail.com
}

Dr. Miguel Lisbona Guillén, director del Centro Peninsular en Humanidades y en Ciencias Sociales (Mérida, Yucatán) de la Universidad Nacional Autónoma de México, institución de la cual es Investigador Titular “B” de Tiempo Completo. Temas de interés: religión y religiosidad, etnicidad, historia cultural de la posrevolución mexicana y migraciones históricas. Entre sus últimas publicaciones está el libro coordinado junto a Antonio Higuera Bonfil titulado El vigor de las imágenes. Miradas interdisciplinarias, PROIMMSE-IIA-UNAM/UQROO, México.

Resumen: Los aportes culturales de los descendientes de chinos en la costa del Pacífico mexicano, concretamente en el estado de Chiapas, han trascendido el carácter anecdótico para convertirse, gracias a la construcción de una tradición gastronómica conocida como comida china, en referente de identidad local, en especial en la ciudad de Tapachula.

Palabras clave: Comida, chinos, inmigración, Soconusco, Chiapas.

Abstract: The cultural contributions of Chinese descendants in the Pacific coast of México, specifically in the state of Chiapas, have transcended the anecdotal nature to become a benchmark of local identity, thanks to the construction of a gastronomic tradition known as Chinese food, especially in the city of Tapachula.

Keywords: Food, chinese, immigration, Soconusco, Chiapas.

Cuadernos de Antropología 2014, 24(1), 75-88

Recibido: 20-08-2013 / Aceptado: 07-03-2014

Revista del Laboratorio de Etnología María Eugenia Bozzoli Vargas Escuela de Antropología, Universidad de Costa Rica http://revistas.ucr.ac.cr/index.php/antropologia ISSN 2215-356X

(c) (i) (-) Cuadernos de Antropología está bajo una licencia Creative Commons Attribution-NonCommercial-ShareAlike 3.0 


\section{Introducción}

La presencia de descendientes de inmigrantes chinos en el estado mexicano de Chiapas, y en concreto en la región costera del Pacífico, conocida como el Soconusco, es referencia constante para hablar de las migraciones históricas en dicho estado y, también, como elemento de identidad cultural local. Esto último parece inverosímil en un territorio caracterizado por la existencia de poblaciones indígenas de origen mayance y zoque, o por las diferencias marcadas en muchos ámbitos de la vida social entre indígenas y no indígenas, aunque no lo es si se observa el vivir cotidiano en algunas regiones chiapanecas y se toma en cuenta la asunción de aspectos culturales en lugares como Tapachula, capital del Soconusco.

Desde el punto de vista de la organización político-administrativa del estado de Chiapas, antes de las reformas efectuadas por el gobernador Juan Sabines (en 2011), la región Soconusco estaba compuesta por 16 municipios, con un nítido centro poblacional: Tapachula. Tal particularidad también inclina la balanza sobre la impronta dejada por la inmigración china en este territorio, puesto que es en esa ciudad donde se aprecia con mayor visibilidad su huella. Tapachula es la segunda ciudad en número de habitantes del estado de Chiapas, aunque estudios realizados a finales del siglo pasado señalaban que su crecimiento urbano, al igual que el del Soconusco, era lento en relación con el resto del país (Camas, 1998).

Si los últimos censos de población no reflejan una inmigración reciente de chinos hacia tierras chiapanecas, ello no encubre que sea un lugar de paso para el trasiego poblacional, especialmente por encontrarse cerca del vecino país de Guatemala. En cuanto al primer aspecto, el que refiere la existencia de inmigrantes recientes a tierras chiapanecas, se puede afirmar que una simple visita a restaurantes especializados en comida china o a otros establecimientos propiedad de descendientes chinos muestra la presencia de trabajadores inmigrantes con poco tiempo en México, hecho que en ninguna forma es ocultado por los propietarios. Incluso en alguna entrevista se refieren a "paisanitos que acaban de llegar, tendrán unos tres meses [...]. Primero llegó su esposo que ya tiene como un año acá. A él lo trajo el tío para que le ayudara en sus negocios y luego se trajeron a la muchacha [esposa]" (Chong, entrevista personal, 2007, febrero, 13). O también se señala que:

Antes muchos se traían a sus parientes, ahora no tanto, todavía en la época de Salinas de Gortari vinieron algunos chinos, se traían a los hermanos, a las cuñadas, algunos que tenían hijos, ahí los trajeron, son gente que viene a trabajar. Está el caso del Yan Yan, ese en poco tiempo creció, se trajo a sus hermanos, pero es de los que llegó recientemente (Inchon Barrios, entrevista personal, 2007, febrero, 13).

En cuanto al segundo aspecto, la prensa chiapaneca ha mostrado, al menos desde el 2004 cuando se empezó a dar seguimiento a esta circunstancia, cómo el tráfico de indocumentados chinos rumbo a los Estados Unidos es persistente en los dos últimos lustros. En ambos casos, es evidente que la emigración 
china sigue siendo una constante del país, como lo confirman los más de 30 millones de ciudadanos de la República Popular China quienes se encontraban fuera de sus fronteras a finales del siglo XX (Hung, 1992).

La huella de la industria agroexportadora de principios del siglo XX sigue siendo perceptible en la actualidad en la región de referencia, a pesar de que el café haya dejado paso a otros cultivos y a la ganadería en su vocación económica. Sin embargo, el café se rememora como parte de la historia regional en forma de presentación turística en una ruta que lleva su nombre, o mediante la reconversión de algunas fincas emblemáticas en hoteles (fincas Argovia y Hamburgo). Tal reconversión de ciertos lugares históricos del Soconusco también afecta al Puerto de San Benito, hoy llamado Puerto Chiapas, con la dudosa esperanza de que los cruceros sobre el Pacífico hagan escala en tierras chiapanecas.

Si en párrafos anteriores se mencionó que la frontera con Centroamérica significa un tráfico de personas, en gran medida lacerante para los migrantes que buscan mejores condiciones de vida lejos de sus países de origen, ello no impide señalar que la costa, y en especial su capital, tiene en la oferta de servicios una de sus vocaciones principales. Condición donde se observa de manera fehaciente la huella de los descendientes chinos, dedicados a la industria restaurantera o a la venta de abarrotes principalmente.

De esta presencia gastronómica surgen manifestaciones como realizada hace algunos años por el periodista Carlos Z. Cadena (2002) al exponer sus ideas sobre cómo promocionar el turismo en dicha ciudad; para él era el momento de reconocer “oficialmente con bombos y platillos que la 'comida china' es una gastronomía local que nos ha dado identidad, y que la mayoría de la que se cocina en la ciudad es ya hecha por manos de chinos tapachultecos". De hecho, sus propuestas van más allá al señalar que se debe:

Levantar una acta donde se declare que la comida china es la carta de presentación e identidad de los tapachultecos. Que un día del año sea declarado como Día de la Comida China [...]. Que cuando menos una vez por mes salga el Dragón Chino a bailar por la ciudad, o en pleno parque central, imponiendo ya una atracción turística que también es historia en Tapachula [...]. Que en el recinto del Kuo Ming Tang, ubicado sobre la cuarta avenida sur, se edifique El Museo Chino, sitio que antes albergó la esencia social y política de los primeros chinos que llegaron a este lugar del Soconusco (Cadena, 2002, p. 3).

Esta circunstancia, que podría parecer anecdótica no lo es si se toma en cuenta que el desaparecido cronista de la ciudad costeña también indicó algo similar antes de su fallecimiento. Javier de León (1998) señaló que se incorporaron a las festividades locales, aspectos traídos por los pobladores descendientes de los chinos que se asentaron en Chiapas. Ejemplo de ello se encuentra en el carnaval, "cerrado con broche de oro por la danza del Dragón Chino, ejecutada por la Comunidad China o por la Escuela de Danzas y Artes Marciales Chinas de Julio Pui Chong, representación que ha tomado ya calidad tradicional”. 
En definitiva, para la ciudad de Tapachula, y en buena parte de los municipios del Soconusco, la histórica inmigración china representa en la actualidad un referente de identificación cultural, aunque tal hecho no haya sido explorado desde las ciencias sociales. Pocos son los análisis que sustentados en investigación de fuentes primarias, o en trabajo de campo exhaustivo, han pretendido ubicar la génesis de esta inmigración a la región, o las formas de organización e integración de dichos pobladores. Salvo algunos textos divulgativos, las referencias a los chinos asentados en la entidad federativa del sureste mexicano deben buscarse en obras de carácter nacional que, de manera colateral, hacen mención a los asiáticos instalados en Chiapas. A pesar de tal particularidad, las siguientes páginas sólo abordarán, en forma de apunte, los orígenes históricos de dicha inmigración, así como el papel que la comida china juega como referente identitario en la región del Soconusco. Un trabajo de mayor amplitud que aborda la génesis de esa migración y la huella contemporánea de la presencia china en Chiapas será publicado próximamente en México, investigación de la que una parte se presenta en las siguientes páginas. En dicho trabajo se utilizaron fuentes históricas primarias de diversos archivos locales y nacionales y fuentes secundarias. Asimismo, se realizó trabajo de campo antropológico y más de 40 entrevistas dirigidas con descendientes de chinos en toda la región del Soconusco, las cuales aportaron informaciones valiosas sobre el pasado reciente y que, a la vez, permiten conocer la construcción de un discurso local sobre la herencia china y la identidad regional o comunitaria, especialmente en la ciudad de Tapachula, Chiapas (México).

\section{Pinceladas históricas: el arribo de los chinos}

El Soconusco, parte de la franja costera entre el océano Pacífico y la Sierra Madre de Chiapas, y que en su nombre lleva uno de sus estandartes históricos, la producción de cacao, registra, hasta el momento, a los primeros pobladores sedentarios conocidos en la región (Clark y Blake, 1989). Cuando los conquistadores castellanos llegaron a la costa del Pacífico, hoy mexicano, los pobladores eran hablantes de algún idioma mixezoqueano, bautizado como tapachulteco por los lingüistas (Kaufman, 1964). Región de exuberante vegetación, y sitio de paso para las conquistas aztecas y su intercambio comercial, se convirtió en un deseado espacio de explotación, tanto así que incluso Miguel de Cervantes Saavedra lo solicitó en encomienda en 1590, aunque se le denegara la concesión (AGN, 2005; García, 1992).

Este territorio, con distintas situaciones jurídicas durante el periodo colonial y en los inicios de las independencias de la América hispana, pasó a formar parte de los Estados Unidos Mexicanos a mediados del siglo XIX, hecho confirmado posteriormente con la firma de un tratado de límites entre México y Guatemala (De Vos, 2010). De igual forma, en los siglos de dominación colonial tuvo un castigo demográfico prácticamente constante, lo que significó la paulatina transformación étnica de sus habitantes y la desaparición de las lenguas indígenas propias. A pesar de ello, en el siglo XIX se erige como una panacea económica para las plantaciones de productos de exportación a gran escala. Españoles, estadounidenses, y 
especialmente alemanes, monopolizaron el cultivo y venta internacional del café (Baumann, 1983; Spenser, 1988), aspecto que incrementó el arribo de población trabajadora de otras partes de Chiapas, y también del extranjero, como fue el caso de los vecinos guatemaltecos y de los chinos.

Si la conquista castellana había sido una posibilidad de evangelización católica de China, en un principio alentada por la confusión geográfica, tal interés se sostuvo una vez se corrigió el error, como lo recuerda Carmelo Lisón (1992). Sin embargo, el camino que se recorrió y que aquí se quiere destacar es el inverso. A finales del siglo XIX, pero especialmente a principios del XX, la paulatina, pero continuada inmigración de chinos hacia el continente americano, a través de diversas modalidades, tiene una constancia observable en el Soconusco.

Según la información documental, no parece claro cuál fue el origen de la migración china a esta región del Pacífico mexicano; sin embargo, es perceptible el incremento de ésta cuando en los Estados Unidos y en ciertos estados del norte mexicano se toman medidas legislativas para prohibir la instalación de tal población e incluso se realizan expulsiones y persecuciones sistemáticas (Salazar, 2006; Yankelevich, 2009).

La Revolución Mexicana y los gobiernos surgidos de este multifacético acontecimiento tendrán entre sus prioridades la construcción de un nuevo ciudadano mexicano y para ello, amparados en las diatribas pseudocientíficas construidas en el siglo XIX, pero prolongadas en el XIX, se toman una serie de medidas que restringirán la llegada de poblaciones asiáticas, consideradas como racialmente degeneradas. Con el objetivo de formar ese nuevo ciudadano transformado mentalmente en pos de alcanzar metas de progreso hasta entonces inimaginables, es posible entender que se desplegaran campañas de muy disímil índole, entre ellas la antichinos. Campañas que tenían todas un denominador común en el marcado puritanismo moral y en la idea de higiene social que incluía, por supuesto, los factores biológicos que se creían involucrados en ésta (Reñique, 2003, Urías, 2007). Por ello es entendible que el surgimiento de Ligas Antichinas en la geografía nacional implicara un posicionamiento nacionalista al mismo tiempo que tenía tintes de xenofobia plasmada en acciones concretas de agresión física, o a través de discursos públicos que convertían a los chinos en ejemplo de degeneración racial y portadores de enfermedades (Gómez, 1991; Monteón y Trueba, 1988), como bien lo recordaba Lisón (1992) al referir que a "la enfermedad hay que hacerla exterior, ajena; viene conceptual y emotivamente asociada al extraño, al Otro".

El territorio chiapaneco no fue indiferente a esta coyuntura, sobre todo porque los chinos que llegaron a trabajar en las fincas agrícolas como braceros, cocineros o lavanderos, paulatinamente establecieron negocios propios en una región cuya expansión económica requería de servicios y, sobre todo, de distribución comercial de productos. Por tal motivo, el comercio, en forma de buhonería, en un principio, o mediante tiendas de abarrotes después, fue acaparado por los chinos instalados en la franja costera chiapaneca y en algunos municipios de la Sierra Madre, como Motozintla. 
Los embates contra estos inmigrantes, sin embargo, no tuvieron el carácter drástico de otros estados de la República Mexicana y la población china, originaria en su mayoría de la provincia de Cantón, pudo establecerse en la región y constituir formas de integración social mediante matrimonios con mexicanas, o creando relaciones personales con políticos en turno, muchas de ellas selladas a través de donaciones de relojes públicos o con la construcción de escuelas y parques, lo anterior gracias a las instituciones que agruparon durante varios años a los chinos inmigrados, que se mencionarán en siguientes párrafos (Lisbona, en prensa).

No es este el espacio para hacer un recuento censal de los chinos que llegaron a la región, ni siquiera su distribución por la geografía de Chiapas, pero ello no impide señalar que en ningún momento se trató de un número que superara el $1 \%$ de la población estatal o regional. La cantidad mayor aparece registrada en el censo de 1930, con un total de 1095 chinos nacidos en el país asiático, puesto que los hijos de chinos o esposas mexicanas de estos también pasaron a ser considerados de tal nacionalidad (Lisbona, 2010; Salazar, 1996). Los controles establecidos por las autoridades migratorias del momento y los datos de los censos así lo confirman, como también muestran los escasos retornos a su país de origen; como mucho se conocen los traslados de hijos de inmigrantes a China para estudiar, con los problemas que algunos de ellos tuvieron para retornar a México una vez instalado el régimen comunista en el país.

Hay que destacar que los chinos que se quedaron adquirieron una posición económica de relevancia gracias al comercio y, a posteriori, mediante los servicios, algunos de ellos ligados ya a la alimentación, como es el caso de los restaurantes. Durante la segunda mitad del siglo XX, la apertura de negocios familiares de comida ofrece un panorama visible hasta nuestros días, donde la oferta gastronómica de la segunda ciudad en población de Chiapas, Tapachula, está ligada a la comida china o, al menos, lo que se denomina comida china, puesto que su elaboración y productos tienen el marcado carácter otorgado a ésta en California. Por lo tanto, la presencia china en la actualidad, si la referencia es el Soconusco chiapaneco, no está unida a un flujo constante de población china como ocurre en la capital del país, el Distrito Federal, o como es visible desde hace varias décadas en el caso español (Nieto, 2007), sino a los descendientes de los originarios inmigrantes. Hoy, tales descendientes son chiapanecos y tienen los mismos derechos y obligaciones que cualquier ciudadano mexicano. El comercio, las profesiones liberales o incluso la política están surcados de apellidos de origen chino.

Debido a lo expuesto, las instituciones históricas de chinos, como el Kuo Ming Tang o Partido Nacionalista Chino, se diluyeron paulatinamente en el tiempo, aunque existen proyectos de revitalización de la llamada "Comunidad China del Soconusco A.C.". A pesar de ello, lo que se observa con nitidez es una marcada integración de lo que se podrían llamar diacríticos chinos en tierras chiapanecas, y el más claro ejemplo lo constituye la comida. 


\section{La comida china entra en escena o cómo construir una identidad}

A finales del 2010, la cocina mexicana fue reconocida por la Unesco como Patrimonio Cultural Inmaterial de la Humanidad, hecho que redunda en aquello que Jesús Contreras (1993) consideró como cocina nacional, por ser sus alimentos y forma de prepararlos algo propio y específico de un determinado país, además de constituirse como un elemento que otorga identidad a un grupo. Sin embargo, esto que podría considerarse lógico y extensible a cualquier parte de la geografía mexicana encuentra, por supuesto, muchos matices locales, y el caso chiapaneco no es la excepción.

En referencia a los Altos de Chiapas, región donde indígenas y ladinos conviven desde hace cinco siglos, ya Pedro Pitarch (1995) apuntó cómo para la elaboración de los alimentos ambos hacen uso de "la tradición cultural de los otros (los ladinos en el ámbito más doméstico y los indígenas en los aspectos más públicos de la cultura)", eso sí, con diferencias, los "indígenas emplean ambas tradiciones alternativamente, pero sin mezclar sus elementos y por tanto distinguiéndolos y manteniéndolos conceptualmente separados, mientras que los ladinos los mezclan activamente hasta no distinguirlos". Tales aseveraciones hablan de un profundo mestizaje gastronómico, visible no solo en regiones compartidas por indígenas y no indígenas, sino en la geografía chiapaneca surcada por grupos humanos de origen prehispánico y por inmigrantes que no solo procedían de la península ibérica. Seguramente, el caso del Soconusco es el que muestra con mayor nitidez esta realidad.

El repunte de la finca agroexportadora en el siglo XIX implicó la llegada de poblaciones de muy distinta procedencia, así como determinó un tipo de producción que incidía, sobre todo, en el mercado externo, más que en el interno. Por tal motivo, y a pesar de ser el territorio de referencia un natural productor de frutas y consumidor de pescados y mariscos, buena parte de los alimentos básicos consumidos tenían otra procedencia. No se puede hablar, entonces, de una cocina propiamente dicha autóctona del lugar, sino que su conformación tiene determinantes surgidos del consumo de la finca, de los productos ya existentes y de los que fueron requeridos comercialmente por los inmigrantes.

El arribo de los chinos, algunos de ellos utilizados como cocineros en las mencionadas fincas, no solo propició una elaboración distinta de ciertos productos y la determinación del género de quienes los preparaban, los hombres, sino que ofreció aquello que Jack Goody (1995) señalaba para los años veinte del siglo pasado en la propia China, una mejor transformación de los alimentos. Es decir, aunque la comida de los trabajadores chinos en su país se sustentaba básicamente en el cereal, su elaboración era cuidada por los cocineros. 
Por lo tanto, la comida china, aunque ya se dijo que para ser más precisos debería llamarse cantonesa, con su espacial énfasis en el arroz (Goody, 1995), no solo formó parte del núcleo de inmigrantes orientales, sino que se incorpora al gusto de los trabajadores de las fincas desde que los chinos llegan a esta región de Chiapas. Dos citas surgidas de entrevistas de la región confirman estas aseveraciones:

Lo que sabemos es que en determinados lugares había chinitos, había chinos pobretones también, porque lo que entiendo desde aquella época es que, además de la habilidad que tenían para el negocio, eran muy diestros para el arte culinario. Entonces el que menos, por lo menos, vendía comida (Morales Reyes, Entrevista personal, 2007, marzo, 6).

Mi papá se llamaba Manuel Liy Ley, vino procedente de Cantón, China, de la tierra de los cocineros [...]. Mi papá dio a conocer 600 platillos que en ese entonces se condimentaban en la gran China, pero aquí él con todos los insumos y verduras que hay aquí, en nuestro México, él decía que se podían hacer de 200 a 300 platillos originales, como si fuera en China, porque había los suficientes materiales, insumos, para trabajarlos. Él nos enseñó a todos [los hijos] a cocinar (Lily Pérez, entrevista personal, 2007, marzo, 22).

El incremento de población china en la región, así como su dedicación al comercio, facilitaron la llegada de productos básicos para la gastronomía oriental, al mismo tiempo que la mayor elaboración de sus guisos, en una zona donde la población no había sido estable en el periodo colonial, a diferencia de otras regiones de Chiapas, dispuso que esta comida adquiriera un cierto estatus y se extendiera su degustación a través de establecimientos de comida.

La historia de la alimentación humana se caracteriza por los cambios y las incorporaciones constantes (Flandrin y Montanari, 1996), y el caso aquí referido remite a ellos como ha ocurrido en otros territorios del ecúmene desde hace siglos, y el antecedente de la pasta en Italia o de la patata en Irlanda son un nítido ejemplo que refuerza acontecimientos más recientes, como la carne con ciruelas marroquí, convertida en estandarte de la cocina de ese país, pero invención reciente, según lo expresado por Isabel González (2009).

La conversión de la comida china en una bandera cultural regional, pero sobre todo de la capital del Soconusco, Tapachula, habla de dos aspectos de relevancia que este texto quiere resaltar; por una parte, la conformación poblacional en espacios construidos en gran medida por la inmigración y; por otra, la labilidad de los aspectos que supuestamente conforman la identidad cultural, en muchos casos asumidos con una profundidad histórica no demostrada. 
Por lo que se refiere al primer punto, y guardando las distancias, la región del Soconusco muestra similitudes con lo estudiado por Christy Shields-Argelès (2008) cuando asevera que la asimilación del otro y la tradición culinaria en Estados Unidos pasan por las diferentes historias de los pueblos que han inmigrado. Es decir, la comida china, aunque enseña regional hoy, no es la única que adquirió un estatus diferencial, pero propio en el lugar, como es perceptible con la alemana identificada en Tapachula con la elaboración de postres. Un descendiente de chinos manifestaba con claridad esta singularidad en la construcción cultural de la capital del Soconusco:

Aquí llegaron muchos por lo mismo de que no había problemas, aquí llegaron alemanes, franceses, ingleses, árabes, judíos, españoles, chinos. Es una ciudad muy cosmopolita. Aquí en los negocios se encontraban puras cosas de importación, tanto comida como ropa, la gente andaba muy elegante con traje y corbata. Yo pienso que la misma hospitalidad de aquí de Tapachula, y que no se vio con recelo que se recibiera a gente de otra parte, permitió que se asentara aquí mucha gente. En particular la china fue una de las razas que más se fusionó con la gente local (Chong, entrevista personal, 2077, febrero, 6).

La construcción de la tradición culinaria en el Soconusco, por lo tanto, se diferencia de otras regiones de Chiapas por hacer visible a los inmigrantes y sus tradiciones culinarias. Esta región bañada por el Pacífico, y fronteriza con Guatemala, no tuvo un número de habitantes estable, ni la presencia indígena propia se prolongó durante muchos años, por lo que su configuración poblacional actual está relacionada con el auge económico de la agroindustria exportadora, elemento fundamental para entender la incorporación de nuevas cocinas en su territorio a través de los inmigrantes.

El otro punto referido en párrafos anteriores, el que remite a la identidad, tampoco está alejado de la inmigración. Si en la actualidad este tema adquiere caracteres muy diversos en los estudios y prácticas cotidianas, tal vez la reflexión sobre migraciones históricas aliente perspectivas o posibilidades diferentes. La inmigración china a Chiapas, sin dejar de recordar los atisbos xenófobos iniciales, permite contrastar las múltiples formas en que se construyen las identidades grupales o territoriales.

Sin referentes hispanos o indígenas nítidos, la identidad cultural tapachulteca contiene muy distintas premisas, y la comida china se visualiza como una de ellas, aunque hay otras de tipo oriental como los bailes del dragón chino en ciertas fiestas locales. La supuesta cohesión de la colonia china en la región, manifestada en sus orígenes a través de agrupaciones como la del Partido Nacionalista Chino (Kuo Min Tang) en los años veinte del siglo pasado y, posteriormente, por la Asociación China del Soconusco A.C. y el Club de Mestizos Chino-Mexicanos, no tiene una continuidad en el tiempo, y la desaparición de estas agrupaciones así lo demuestra, aunque en la actualidad varios descendientes de chinos están pugnando 
por revitalizar la Asociación y recuperar la casa que albergó al Kuo Min Tang. Si estas formas de organización, o de imaginarse como comunidad, permitieron generar un cierto sentido de identidad nacional entre los inmigrantes chinos (Delgado, 1998), no es menos cierto que lo que prevaleció entre los llegados de oriente fue una progresiva integración por diversos mecanismos personales y laborales; ésta facilitó la asunción de ciertos diacríticos culturales como representantes de la identidad local tapachulteca. La diferencia cultural aportada por los chinos adquirió el carácter de realidad cultural propia, y tal hecho habría que pensarlo, aunque fuera hipotéticamente, debido a que en el Soconusco las identificaciones culturales existentes en otras regiones de Chiapas como marcadores étnicos no estaban presentes, más bien eran las divisiones jerárquicas sustentadas en el poder económico las que se privilegiaron.

No cabe duda que la construcción de México como nación, pretendida cultural, ha estado tensada por la relación entre indígenas y no indígenas desde el siglo XIX y, en tal sentido, la constante llegada de inmigrantes ha sido asumida desde la intromisión de cuerpos ajenos que pasan por sus supuestos aportes culturales, siempre estableciendo diferencias con una deseada población nacional homogénea y también mestiza. El caso de los chinos en Chiapas es significativo porque, aunque tomados como grupo o creado dicho grupo por los mismos inmigrantes, muestra que las pensadas diferencias se diluyen hasta el punto de engrosar la realidad local y convertirse en una referencia de identidad. Tal vez sea el momento de poner en cuarentena las llamadas raíces de México -raíces entendidas como nichos culturales- y dedicarse a observar y describir los procesos que han dado pie a situaciones como la vivida en la costa chiapaneca.

\section{Reflexión final}

Si es "un error exagerar las continuidades en la cultura de la comida" (Goody, 1995, p. 192), parece una desproporción, aunque se haya convertido en un hábito, considerar que lo ocurrido en todo el territorio chiapaneco es, como lo criticó Pitarch (1995), “una reiteración simple de tiempos anteriores, 'coloniales” o prerevolucionarios: allí el tiempo no avanza, se limita a repetirse”. Lo expuesto en estas páginas, de manera resumida y sin posibilidad de extensión en algunos puntos concretos, evidencia que en la conformación de un estado federativo como el de Chiapas, las historias regionales muestran situaciones diferenciadas a la hora de establecer sus marcadores identitarios históricos.

La presencia china, foco de tensión en el norte de México en las primeras cuatro décadas del siglo $\mathrm{XX}$, y que continúa mostrando puntos de rechazo en países como España, tal como lo demuestra el trabajo de Gladys Nieto (2007), se ha convertido en Tapachula en una existencia asumida como propia, hasta el punto de que la comida denominada china es un estandarte de la ciudad y no deja de asomarse en toda la mancha urbana a través de un sinnúmero de negocios dedicados a dicha especialidad gastronómica. Ir al 
Soconusco y no degustar alguno de los platos ofrecidos en sus restaurantes de comida china, o los preparados en las casas particulares, aunque éstas no tengan entre sus antepasados a inmigrantes orientales, no deja de ser observado con inquietud por los anfitriones, puesto que es su comida local. Algo que es aseverado por los descendientes de chinos:

Yo siento que en lo que es la zona de la costa [...] siento que la comida es una de las herencias que han dejado los chinos [...]. Aquí en cualquier casa de los tapachultecos se sabe guisar un chop suey, un arroz cantonés, como sea, a como lo ve la gente. La gente agarra y hace el intento porque hay todos los medios para hacerlo, se encuentran todos los condimentos para hacerlo. De hecho mucha gente de la que viene pregunta ¿cuál es la comida típica en Tapachula?, y le dicen que es la comida china. Culturalmente yo creo que ese ha sido un gran aporte (Chong, entrevista personal, 2077, febrero, 7).

Tales expresiones llaman, sin lugar a dudas, a una observación más detallada de los aspectos históricos de una localidad o región a la hora de establecer o enumerar diacríticos culturales referidos, en este caso, a la comida. Para el ejemplo abordado en estas páginas, tal afirmación permite destacar cómo la inmigración no puede entenderse como la incorporación de un grupo uniforme sobre una realidad social y cultural dada; por el contrario, la presencia de chinos en Chiapas y la derivación de su llamada comida en un referente de identidad local interrogan y cuestionan, a la vez, sobre las múltiples facetas que la inmigración ha tenido y sigue teniendo en la vida cultural de las sociedades humanas.

\section{Referencias bibliográficas}

Archivo General de la Nación (AGN), (2005). El Soconusco cervantino: cartografía de una encomienda imaginaria [DVD]. México: AGN/Ministerio de Cultura de España.

Baumann, F. (1983). Terratenientes, campesinos y la expansión de la agricultura capitalista en Chiapas, 1896-1916. Mesoamérica, 4(5), 8-63.

Cadena, C. Z. (2002). Comentario Zeta. El Orbe, 4.

Camas, F. J. (1998). El desarrollo económico del Soconusco y el crecimiento demográfico y territorial de Tapachula, 1880-1990. En V. M. Muro (coord.), Ciudades provincianas de México. Historia, modernización y cambio cultural (pp. 219-239). México: COLMICH.

Clark, J. E. y Blake, M. (1989). El origen de la civilización en Mesoamérica: los olmecas y mokayas del Soconusco de Chiapas, México. En M. Carmona. (coord.), El preclásico o formativo. Avances y perspectivas (pp. 385-403). México: INAH. 
Contreras, J. (1993). Antropología de la alimentación. Madrid: Eudema.

Corbeau, J-P. (2008). Itinéraires de mangeurs. En J-P. Corbeau y J-P. Poulain, Penser L'alimentation. Entre imaginaire et rationalité (pp. 23-134). Toulouse: Privat.

De León, J. (1998). Presencia china en Tapachula. El Orbe, 3-6.

De Vos, J. (2010). Vienen de lejos los torrentes. Una historia de Chiapas. Tuxtla Gutiérrez: Consejo Estatal para las Culturas y las Artes.

Delgado, M. (1998). Diversitat i integració. Lògica i dinámica de les identitats a Catalunya. Barcelona: Empúries.

Flandrin, J. L. y Montanari, M. (eds) (1996). Histoire de l'alimentation. París: Fayard.

García, A. (1992). La verdadera historia de un tal Miguel de Cervantes, gobernador del Soconusco. Suplemento cultural de La Jornada.

Gómez, J. J. (1991). El movimiento antichino en México (1871-1934). Problemas del racismo y del nacionalismo durante la Revolución Mexicana. México D.F.: INAH.

González, I. (2009). La frontera como horizonte culinario: Andalucía y Marruecos. En F. X. Medina, R. Ávila e I. De Garine (coords.), Food, Imaginaries and Cultural Frontiers. Essays in Honour of Helen Macbeth (pp. 319-331). Guadalajara: Universidad de Guadalajara.

Goody, J. (1995). Cocina, cuisine y clase. Estudio de sociología comparada. Barcelona: Gedisa.

Hung, J. (1992). Chinos en América. Madrid: Editorial Mapfre.

Kaufman, S. (1964). Mixe-zoque subgrups and the position of tapachulteco. En Actas y Memorias del XXXV Congreso Internacional de Americanistas, Tomo II (pp. 403-411). México D.F.: INAH.

Lisbona, M. (2010). Acercamiento a los estudios sobre la población china de Chiapas: problemas de investigación antropológica a la luz de los datos históricos. Anuario de Investigación del Centro de Estudios Superiores de México y Centroamérica, 2008, 233-250.

Lisbona, M. (en prensa). Allí donde lleguen las olas del mar... Pasado y presente de los chinos en Chiapas. México D. F.: PROIMMSE-IIA-UNAM/CONECULTA.

Lisón, C. (1992). Individuo, estructura y creatividad. Etopeyas desde la antropología cultural. Madrid: Akal.

Monteón, H. y Trueba, J. L. (1988). Chinos y Antichinos en México. Documentos para su estudio. México D.F.: Unidad Editorial-Gobierno de Jalisco.

Nieto, G. (2007). La inmigración china en España. Una comunidad ligada a su nación. Madrid: Universidad Autónoma de Madrid.

Pitarch, P. (1995). Un lugar difícil: estereotipos étnicos y juegos de poder en los Altos de Chiapa". En J. P. Viqueira y M. H. Ruz (eds), Chiapas. Los rumbos de otra historia (pp. 237-250). México D.F.: UNAM-CIESAS-CEMCA-UdG.

Reñique, G. (2003). Región, raza y nación en el antichinismo sonorense. En A. Grageda (coord.). Seis expulsiones y un adiós. Despojos y expulsiones en Sonora (pp. 231-289). México: UNISON/Plaza y Valdés Editores.

Salazar, D. (1996). La población extranjera en México (1895-1990). Un recuento con base en los censos generales de población. México: INAH.

http://revistas.ucr.ac.cr/index.php/antropologia 
Salazar, D. (coord.) (2006). Xenofobia y xenofilia en la historia de México, siglos XIX y XX. México D.F.: Segob-INAH-DGE Ediciones.

Shields-Argelès, C. (2008). Alimentation et identité nationale: le soi et l'autre en France et aux États-Unis. En C. Fischler y E. Masson (eds.), Manger. Français, Européens et Américains face à l'alimentation (250-269). París: Odile Jacob.

Spenser, D. (1988). Los inicios del cultivo del café en Soconusco y la inmigración extranjer”. En B. von Mentz B. (ed.), Los empresarios alemanes, el Tercer Reich y la oposición de derecha a Cárdenas, Tomo I (61-87). México D.F.: Centro de Investigaciones y Estudios Superiores en Antropología Social.

Urías, B. (2007). Historias secretas del racismo en México (1920-1950). México: Tusquets Editores.

Yankelevich, P. (coord.) (2009). Nación y extranjería. La exclusión racial en las políticas migratorias de Argentina, Brasil, Cuba y México. México D.F.: UNAM. 
